\title{
Using ship-borne observations of methane isotopic ratio in the Arctic Ocean to understand methane sources in the Arctic
}

Antoine Berchet et al.

Correspondence to: Antoine Berchet (antoine.berchet@1sce.ipsl.fr)

The copyright of individual parts of the supplement might differ from the CC BY 4.0 License. 


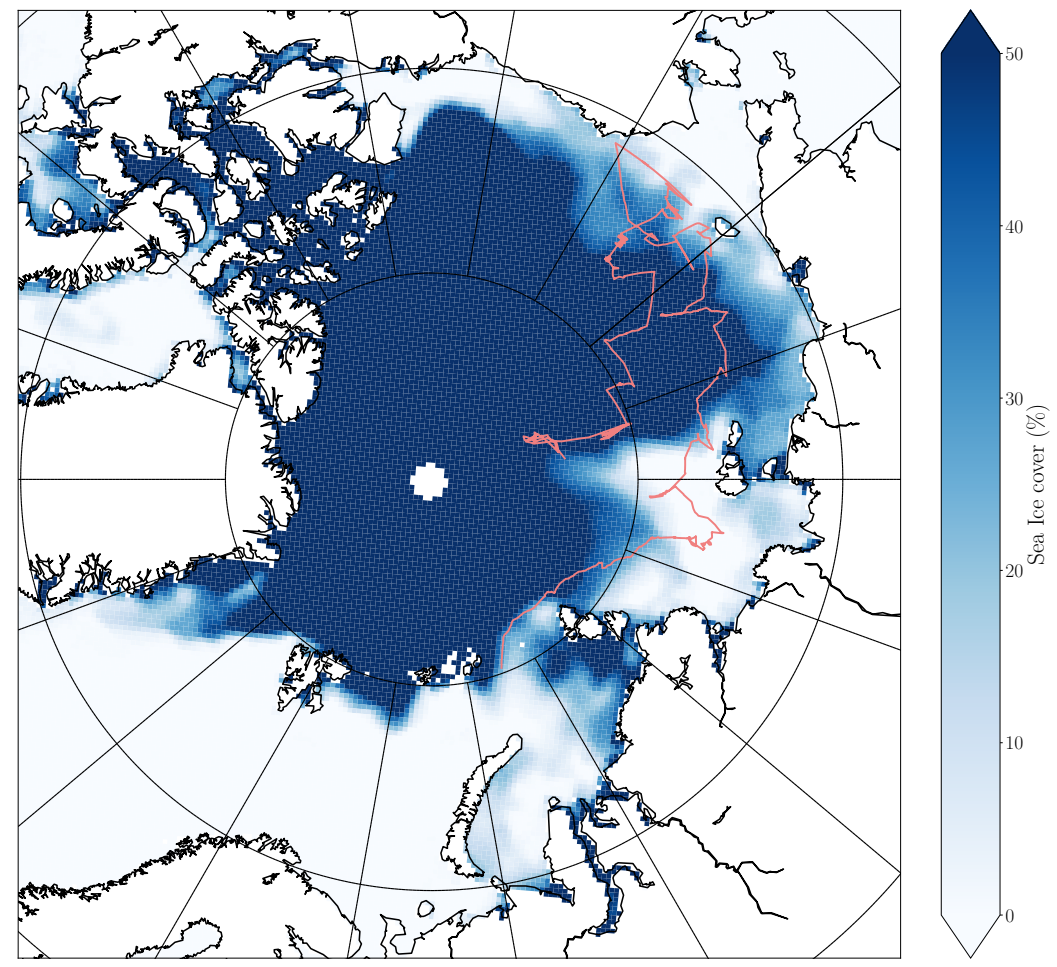

Figure S1. Average Sea Ice cover during summer 2014 (July-August). Data from NOAA/NSIDC passive microwave sea ice concentration climate data record (Comiso and Nishio, 2008). 


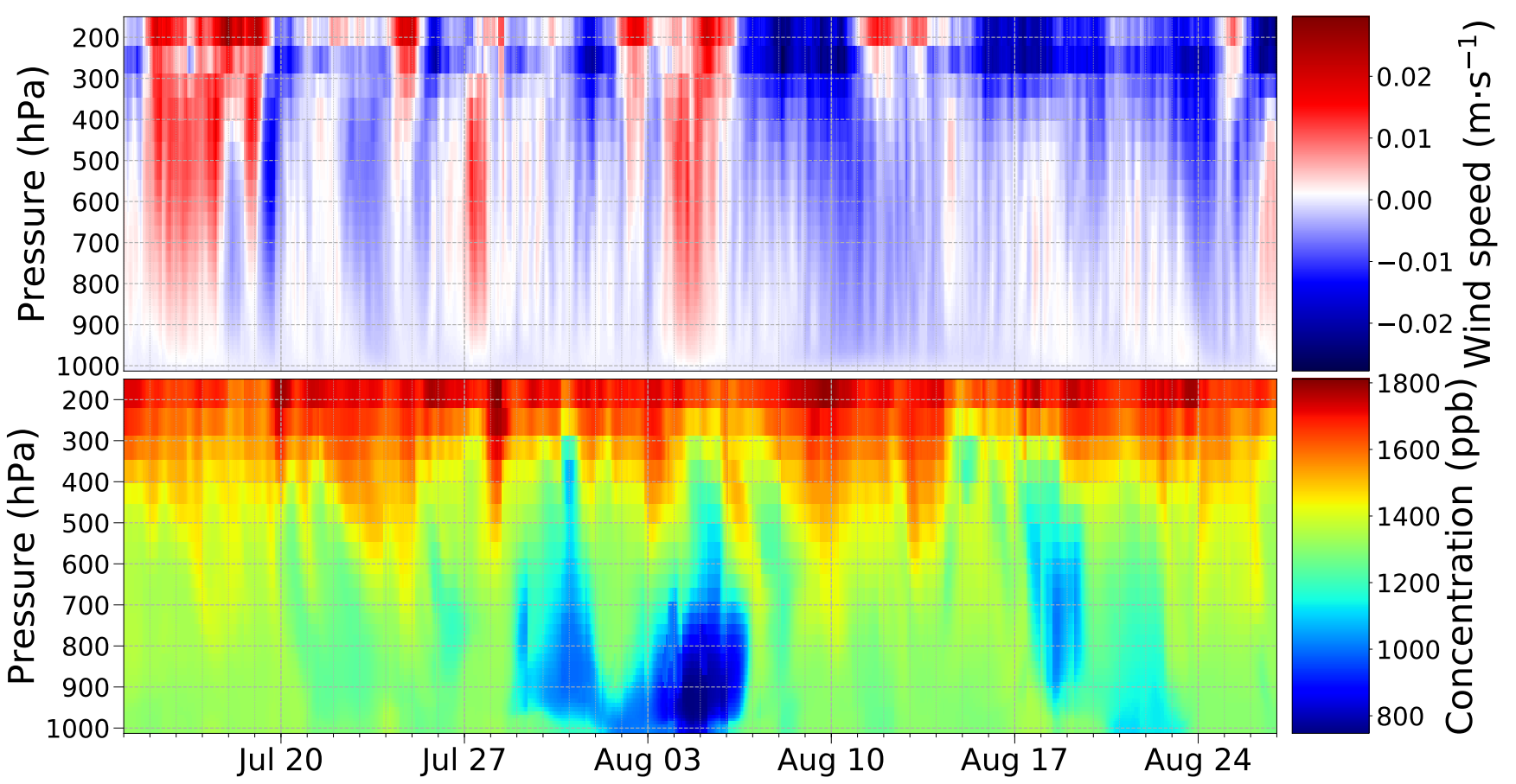

Figure S2. Curtains plot of vertical wind speed (top panel) and simulated concentration from the top of the domain (bottom panel)

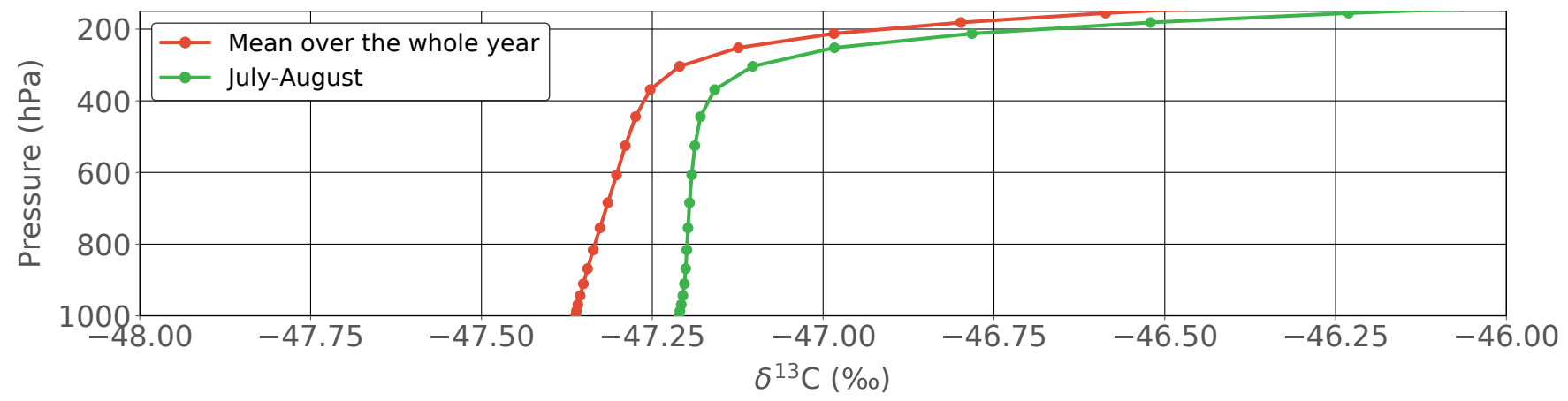

Figure S3. Vertical distribution of isotopic ratio as simulated by the model LMDZ averaged over the Arctic ocean for the year 2014 . 


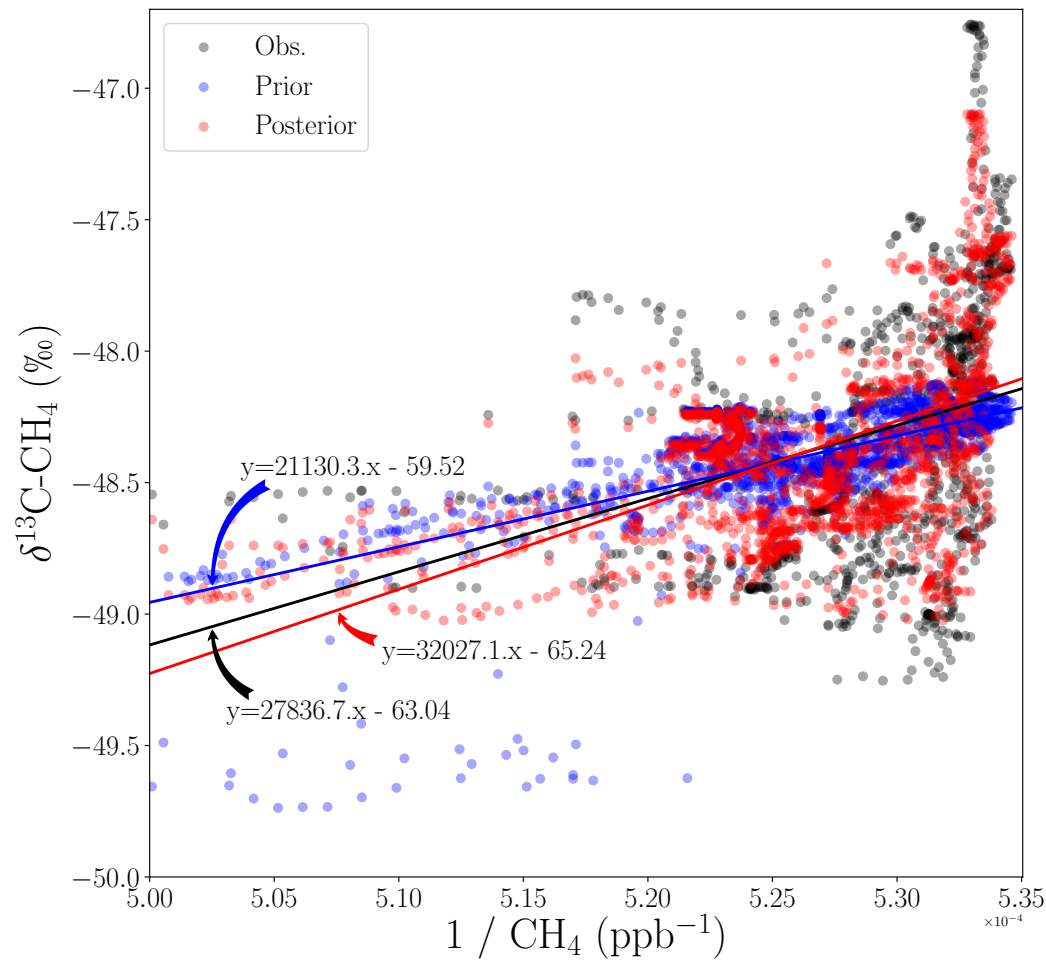

Figure S4. Keeling plot for the observed (black) and simulated (blue/red before/after inversion) $\delta^{13} \mathrm{C}^{-} \mathrm{CH}_{4}$ during the campaign. 


\section{References}

Comiso, J. C. and Nishio, F.: Trends in the sea ice cover using enhanced and compatible AMSR-E, SSM/I, and SMMR data, Journal of Geophysical Research: Oceans, 113, https://doi.org/10.1029/2007JC004257, https://agupubs.onlinelibrary.wiley.com/doi/abs/10.1029/ 2007JC004257, 2008. 